\title{
Towards Closing the Surface Energy Budget of a Mid-latitude Grassland
}

\author{
Adrie F. G. Jacobs • Bert G. Heusinkveld • \\ Albert A. M. Holtslag
}

Received: 10 October 2006 / Accepted: 25 June 2007 / Published online: 20 July 2007

(C) Springer Science+Business Media B.V. 2007

\begin{abstract}
Observations for May and August, 2005, from a long-term grassland meteorological station situated in central Netherlands were used to evaluate the closure of the surface energy budget. We compute all possible enthalpy changes, such as the grass cover heat storage, dew water heat storage, air mass heat storage and the photosynthesis energy flux, over an averaging time interval. In addition, the soil heat flux was estimated using a harmonic analysis technique to obtain a more accurate assessment of the surface soil heat flux. By doing so, a closure of $96 \%$ was obtained. The harmonic analysis technique appears to improve closure by $9 \%$, the photosynthesis for $3 \%$ and the rest of the storage terms for a $3 \%$ improvement of the energy budget closure. For calm nights (friction velocity $u_{*}<0.1 \mathrm{~m} \mathrm{~s}^{-1}$ ) when the eddy covariance technique is unreliable for measurement of the vertical turbulent fluxes, the inclusion of a scheme that calculates dew fluxes improves the energy budget closure significantly.
\end{abstract}

Keywords Grassland · Photosynthesis $\cdot$ Soil heat flux $\cdot$ Surface energy budget $\cdot$ Surface energy budget closure

\section{Introduction}

A serious deficiency is typically present when measuring the total energy budget near the earth's surface, such that the available energy (net radiation minus soil heat flux) is larger than the sum of the vertical turbulent heat fluxes (sensible heat plus evapotranspiration). The ratio of heat fluxes to available energy, often called the recovery ratio, ranges between 70 and 90\% for various ecosystems (Wilson et al. 2002; Foken 2006; Foken et al. 2006). The main reasons attributed to this large gap include instrumental errors, especially those related to the eddy covariance technique (Foken and Wichura 1996), the energy storage in

A. F. G. Jacobs $(\varangle)$ · B. G. Heusinkveld · A. A. M. Holtslag

Meteorology and Air Quality Group, Wageningen University, PO Box 476700 AA Wageningen,

The Netherlands

e-mail: adrie.jacobs@wur.nl 
the soil-vegetation-atmosphere system (Braud et al. 1993; Bolle et al. 1993), and the loss of low frequency components in the flux-averaging procedure (Sakai et al. 2001; Von Randow et al. 2002; Finnegan et al. 2003). In addition, heterogeneities in the surrounding area can contribute to the non-closure of the surface energy budget (Tsvang et al. 1991).

Recently a new measurement approach was used to estimate the soil heat flux very close to the surface of a bare soil desert ecosystem (Heusinkveld et al. 2004). The measured surface soil heat flux was compared with the traditional surface soil heat flux estimated by measuring the soil heat flux at a certain depth, corrected for soil heat storage above the plate (caloric technique; see e.g., Fritschen and Gay 1979). The caloric technique, however, deviated much from the actual measured surface soil heat flux. A much better result was obtained by using the harmonic analysis technique in estimating the surface soil heat flux, and by applying this technique, a nearly perfect closed energy budget was achieved in the dry desert ecosystem (Heusinkveld et al. 2004).

For bare soil ecosystems, but also for a relatively short grass cover, the contribution of the soil heat flux in the surface energy balance can be considerable (Verhoef 1995; Mayocchi and Bristow 1995). For example, in a desert ecosystem the soil heat flux can be greater than $30 \%$ of the net radiation (Heusinkveld et al. 2004). This suggests that the buried heat flux plate must measure the soil heat flux very accurately and the soil temperature profile above the heat flux plate must be very detailed in order to adequately correct for the soil heat storage. In most cases, including the present study, only one soil temperature measurement is made. This limits the accuracy for the caloric correction, especially for the higher harmonics present in the uppermost soil layer. The harmonic analysis technique better accounts for these high harmonics and thus provides an improved assessment of the surface heat flux (Heusinkveld et al. 2004).

The vertical turbulent heat fluxes (sensible and latent heat) are usually measured above a short vegetated surface at heights ranging between 3 and $6 \mathrm{~m}$, but the heat storage in the vegetation-air system is often ignored. Only for tall canopies and in forested ecosystems is the stored heat in the biomass normally accounted for in the energy budget (McCaughy and Saxton 1988). In assessing these storage terms in agricultural crop systems it appears that indeed these terms are small but are not negligible (Braud et al. 1993; Meyers and Hollinger 2004; Heusinkveld et al. 2004).

In the photosynthesis process, energy is needed to store solar energy in the bonds of carbohydrates (Nobel 1974), though this energy term is nearly always neglected since the conversion energy is thought to be small. In a recent study, however, Meyers and Hollinger (2004) showed that the imbalance for a maize crop could be improved by $15 \%$ and for a soybean crop by $7 \%$ if the energy per mole of $\mathrm{CO}_{2}$ fixed by photosynthesis was taken into account.

The objective of the present study is, (1) to evaluate the energy budget closure for a mid-latitude grassland site, (2) to evaluate the contribution of the surface soil heat flux as calculated with different techniques, (3) to estimate the energy storage caused by the photosynthesis process, and (4) to make an assessment of all possible energy storage terms of the soil-vegetation-air system and to investigate its role in the recovery ratio.

\section{Experimental Set-Up}

Wageningen University operates a long-term meteorological observatory, the Haarweg Station, in the centre of Netherlands (lat. $51^{\circ} 58^{\prime} \mathrm{N}$, long. $5^{\circ} 38^{\prime} \mathrm{W}$, altitude $7 \mathrm{~m}$ a.s.l.; www.met.wau.nl). The region is grassland mainly covered with perennial species of 
ryegrass (Lolium perenne L.) and rough bluegrass (Poa trivialis L.). During the growing season (1 May-1 November), the grass cover is mowed weekly, has a mean height of $0.1 \mathrm{~m}$ and a mean leaf area index, LAI, of 2.9 (Snel 2004). The LAI of the grass cover was estimated with a digital plant canopy imager (CID Inc., type CI-110). The soil at the site is predominantly heavy basin clay resulting from the back-swamps of the Rhine river.

An aspirated psychrometer measures the air temperature, $T_{a}$, and wet-bulb temperature, $T_{w}$, at a reference height $z_{r}=1.5 \mathrm{~m}$. At $0.10 \mathrm{~m}$ height the air temperature $T_{a}(0.10 \mathrm{~m})$ is measured with a shielded Pt-100 thermometer (home-made). The incoming $\left(R_{g i}\right)$ and outgoing $\left(R_{g o}\right)$ shortwave radiation fluxes are measured with an aspirated pyranometer (Kipp \& Zonen, model CM11) at a height of $1.5 \mathrm{~m}$. At the same height, the incoming $\left(R_{L i}\right)$ and outgoing $\left(R_{L o}\right)$ longwave radiation fluxes are measured with a pyrgeometer (Kipp \& Zonen, model CG 1$)$. The outgoing longwave radiation was used to evaluate the surface temperature $T_{S}\left(T_{S}=\left(\frac{R_{L o}}{\varepsilon \sigma}\right)^{1 / 4}\right)$, where $\varepsilon$ is the emissivity of the grass cover $(\varepsilon=0.99)$ and $\sigma$ is Stefan Boltzmann's constant $\left(\sigma=5.67 \times 10^{-8} \mathrm{~W} \mathrm{~K}^{-4} \mathrm{~m}^{-2}\right)$. The net radiation, $Q^{*}$, is determined by summing up the total radiation budget. The longwave radiometers, however, have a small sensitivity to shortwave radiation $\left(15 \mathrm{~W} \mathrm{~m}^{-2}\right.$ at full sunshine) and this thus affects the net radiation. A correction is therefore applied according to the specifications of the manufacturer (Kipp CG2 specifications):

$$
Q^{*}=Q_{m}^{*}-15(1-\alpha) \frac{R_{g i}}{R_{g i}^{\max }}
$$

where $Q_{m}^{*}$ is the measured net radiation, $\alpha$ is the albedo of the underlying surface and $R_{g i}^{\max }$ is the maximum possible global irradiation, taken to be $1,000 \mathrm{~W} \mathrm{~m}^{-2}$. In our case, the underlying surface is a grass cover with an albedo of $\alpha=0.24$ (Campbell and Norman 1998).

Soil temperatures, $T_{s o}$, are measured by Pt-100 elements at depths of $0.05,0.10,0.20,0.50$ and $1.0 \mathrm{~m}$; at $0.01,0.10$ and $0.50 \mathrm{~m}$ depths the soil moisture content was measured with a Time Domain Reflectrometry (TDR) system (Campbell Sci., TDR 100, probe type CS 610). The soil heat flux is measured by a heat plate (TNO, WS 31-Cp) buried at a depth of $75 \mathrm{~mm}$, and the measured soil heat fluxes are corrected for instrumental shape correction, $\Phi$, for soil heat flux sensors as proposed by Mogensen (1970):

$$
\Phi=\frac{1}{1-1.7 t A^{-0.5}\left(1-\varepsilon_{p}^{-1}\right)} .
$$

Here $t=2 \mathrm{~mm}$ is the thickness of the plate, $A$ the area of the plate (plate diameter $0.11 \mathrm{~m}$ ) and $\varepsilon_{p}$ the ratio between the thermal conductivity of the plate to that of the soil. The thermal conductivity of the flux plate was provided by the manufacturer $\left(\lambda_{p}=0.14 \mathrm{~W} \mathrm{~m}^{-1} \mathrm{~K}^{-1}\right)$ and the soil conductivity, $\lambda_{s}$, was measured by the heat needle technique (De Vries 1963) and ranged between 1.0 and $1.3 \mathrm{~W} \mathrm{~m}^{-1} \mathrm{~K}^{-1}$, depending on the soil moisture. The measured soil heat fluxes were corrected for the soil heat storage above the heat flux plate (Fritschen and Gay 1979) according to:

$$
G_{o c}=G_{m}\left(z_{p}\right)-C_{s} \int_{z_{p}}^{0} \frac{\delta T}{\delta t} d z,
$$

where $G_{o c}$ is the caloric soil surface heat flux, $G_{m}$ is the measured soil heat flux, $z_{p}$ is the depth of the soil heat flux plate, and $C_{S}$ is the volumetric heat capacity of the soil. Moreover, the surface soil heat flux was also calculated with the harmonic analysis technique by using the soil temperature at $50 \mathrm{~mm}$ and the measured soil heat flux at $75 \mathrm{~mm}$, indicated as the 
$G_{o h}$ soil heat flux. A detailed description of this harmonic analysis technique can be found elsewhere (Heusinkveld et al. 2004).

Apart from standard agrometeorological measurements, turbulent fluxes of momentum, heat and mass $\left(\mathrm{H}_{2} \mathrm{O}\right.$ and $\left.\mathrm{CO}_{2}\right)$ are measured as well. A lattice tower at the Haarweg station is instrumented with an eddy covariance system installed at a height of $3.5 \mathrm{~m}$. This system includes a three-dimensional sonic anemometer (3-D Solent Res. Gill Instruments Ltd., model A1012R2), a fine wire thermocouple (home-made) and an open path infrared $\mathrm{CO}_{2}$ and $\mathrm{H}_{2} \mathrm{O}$ gas analyser (IRGA) (LI-COR Inc., model LI-7500). The 3-D sonic anemometer and the IRGA are set $0.05 \mathrm{~m}$ apart.

The cumulative source area contribution of the turbulent flux measurements was estimated by calculating the so-called integrated footprint after Schuepp et al. (1990). More than 95\% of the cumulative flux stems from undisturbed grassed area $(x<700 \mathrm{~m})$, except for the wind direction sector $080^{\circ}<\varphi<120^{\circ}$. From this sector only $6 \%$ contributes to the flux and was ignored in the present study.

The slow response meteorological instruments are sampled at $0.25 \mathrm{~Hz}$, and at $30-\mathrm{min}$ intervals data are averaged and stored in data loggers for subsequent processing. The fast response sonic anemometer, the IRGA system and the fine wire thermocouple are sampled at $20.8 \mathrm{~Hz}$. The raw data of the eddy covariance system are stored on a PC and processed at 30-min intervals. More details about the experiments, the measurement site and the data processing can be found in Jacobs et al. (2003).

\section{Methodology}

At the earth's surface, the available energy, $A\left(\mathrm{~W} \mathrm{~m}^{-2}\right)$, which is the net radiation, $Q^{*}\left(\mathrm{~W} \mathrm{~m}^{-2}\right)$ minus the surface soil heat flux, $G_{o}\left(\mathrm{~W} \mathrm{~m}^{-2}\right)$, should balance the sensible heat flux, $H\left(\mathrm{~W} \mathrm{~m}^{-2}\right)$ and the latent heat flux, $L_{v} E\left(\mathrm{~W} \mathrm{~m}^{-2}\right)$ according to:

$$
A=Q^{*}-G_{o}=H+L_{v} E,
$$

where $L_{v}\left(\mathrm{~J} \mathrm{~kg}^{-1}\right)$ is the latent heat for vaporization and $E$ is evaporation. In practice, however, (4) results in a serious imbalance for many ecosystems (Wilson et al. 2002). As mentioned by Meyers and Hollinger (2004), for example, potential reasons for this lack of closure include loss of low frequency components in the flux averaging procedure and lack of an accurate accounting of all storage terms. The surface energy budget equation can be completed with these storage terms according to (e.g., Heusinkveld et al. 2004; Meyers and Hollinger 2004; Foken et al. 2006):

$$
A=Q^{*}-G_{o}=H+L_{v} E+S_{p}+S_{c}+S_{a}+S_{d}+S_{q},
$$

where $S_{p}\left(\mathrm{~W} \mathrm{~m}^{-2}\right)$ is the photosynthesis flux, $S_{c}\left(\mathrm{~W} \mathrm{~m}^{-2}\right)$ is the crop enthalpy change, $S_{a}$ $\left(\mathrm{W} \mathrm{m}^{-2}\right)$ is the air enthalpy change, $S_{d}\left(\mathrm{~W} \mathrm{~m}^{-2}\right)$ is the canopy dew water enthalpy change and $S_{q}\left(\mathrm{~W} \mathrm{~m}^{-2}\right)$ is the atmospheric moisture change. The storage changes are calculated over the measurement averaging time interval of $30 \mathrm{~min}$.

The photosynthesis flux is the change in the Gibbs free energy and can be evaluated with the conversion of $1 \mathrm{mg} \mathrm{CO}_{2} \mathrm{~m}^{-2} \mathrm{~s}^{-1}$ canopy assimilation equal to $11 \mathrm{~W} \mathrm{~m}^{-2}$ (Nobel 1974; Meyers and Hollinger 2004). In this study, the canopy assimilation flux is calculated by using an extended assimilation model (for details, see Jacobs et al. 2003). The crop enthalpy change is:

$$
S_{c}=\frac{\Delta T\left(m_{w} C_{w}+m_{o m} C_{o m}\right)}{\Delta t},
$$


Table 1 Numerical values of some grass cover parameters used in the present study according to Atzema (1993)

\begin{tabular}{lll}
\hline & $\mathrm{m}\left(\mathrm{kg} \mathrm{m}^{-2}\right)$ & $\mathrm{C}\left(\mathrm{J} \mathrm{kg}^{-1} \mathrm{~K}^{-1}\right)$ \\
\hline Water & 1.5 & 4190 \\
Organic matter & 0.2 & 1920
\end{tabular}

where $\Delta T(\mathrm{~K})$ is the grass cover temperature change, with $T$ taken to be the surface temperature, $T_{s}, m_{w}\left(\mathrm{~kg} \mathrm{~m}^{-2}\right)$ and $m_{o m}\left(\mathrm{~kg} \mathrm{~m}^{-2}\right)$ are the masses of water and organic matter, respectively, $C_{w}\left(\mathrm{~J} \mathrm{~kg}^{-1} \mathrm{~K}^{-1}\right)$ and $C_{o m}\left(\mathrm{~J} \mathrm{~kg}^{-1} \mathrm{~K}^{-1}\right)$ are the specific heat capacities of water and organic matter, respectively and $\Delta t(\mathrm{~s})$ is the time averaging interval. The numerical values of the heat capacities and masses used here are taken from Atzema (1993) and are listed in Table 1. The air enthalpy change is:

$$
S_{a}=\rho_{a} C_{a} \int_{0}^{h} \frac{\delta T_{a}}{\delta t} d z,
$$

where $\rho_{a}\left(\mathrm{~kg} \mathrm{~m}^{-3}\right)$ is air density, $T_{a}\left({ }^{\circ} \mathrm{C}\right)$ is air temperature, $C_{a}\left(\mathrm{~J} \mathrm{~kg}^{-1} \mathrm{~K}^{-1}\right)$ is the specific heat capacity for moist air, and $h$ is the height of the eddy covariance system. The atmospheric moisture change is:

$$
S_{q}=L_{v} \int_{0}^{h} \frac{\delta q}{\delta t} d z
$$

and $q\left(\mathrm{~kg} \mathrm{~m}^{-3}\right)$ is the atmospheric moisture density. The canopy dew water enthalpy change is:

$$
S_{d}=\frac{m_{d} C_{w} \Delta T}{\Delta t}
$$

where $m_{d}$ is the mass of dew water within the canopy.

The amount of dew within the grass cover can be calculated from (Garratt and Segal 1988; Holtslag and De Bruin 1988; Jacobs et al. 2006a):

$$
L_{v} E=\frac{s}{s+\gamma}\left(Q^{*}-G_{o}\right)+\frac{\gamma}{s+\gamma} \frac{\rho_{a} L_{v} \delta r}{r_{a v}},
$$

where, $s\left(\mathrm{~K}^{-1}\right)$ is the slope of the saturation mixing ratio curve, $r$ is the mixing ratio $\left(\mathrm{kg} \mathrm{kg}^{-1}\right)$, $\gamma=\frac{C_{p}}{L_{v}}\left(\mathrm{~K}^{-1}\right)$ is the psychrometric constant, $\delta r=r^{*}\left(T_{a}\right)-r\left(\mathrm{~kg} \mathrm{~kg}^{-1}\right)$ is the mixing ratio deficit at reference level, where $r^{*}$ is the saturated mixing ratio, and $r_{a v}$, is the aerodynamic resistance to vapour transport (Garratt 1992). The accumulated amount of dew within the grass cover is given by summing the negative evaporation according to:

$$
D_{i+1}=D_{i}-E_{i} \Delta t
$$

if $D_{i+1} \geq 0$

$$
D_{i+1}=0
$$

if $D_{i}-E_{i} \Delta t<0$, and where $D_{i+1}$ is the new accumulated dew amount, $D_{i}$ is the former dew amount, $E_{i}$ is the dew flux density calculated using (10), and $\Delta t(=1,800 \mathrm{~s})$ is the timestep. If $D_{i}-E_{i} \Delta t<0, D_{i+1}$ is set to zero since this means that all free water on the leaves has evaporated. It must be noted that with (10) the dew amount can be calculated for low vegetation such as a grass cover (Jacobs et al. 2006a), but for tall vegetation (i.e. maize, 
Fig. 1 Course of the daily mean air temperature $\left(T_{a}\right)$, daily total precipitation $(P)$, daily mean short wave incoming $\left(R_{g i}\right)$ and net radiation $\left(Q^{*}\right)$ for May 2005
Fig. 2 Scattergram of the 30-min averages of the available energy versus the convective terms for May 2005. The surface soil heat flux, $G_{o c}$, is calculated with the caloric technique. Rain periods are discarded because of malfunction of the radiometers and EC system during these events
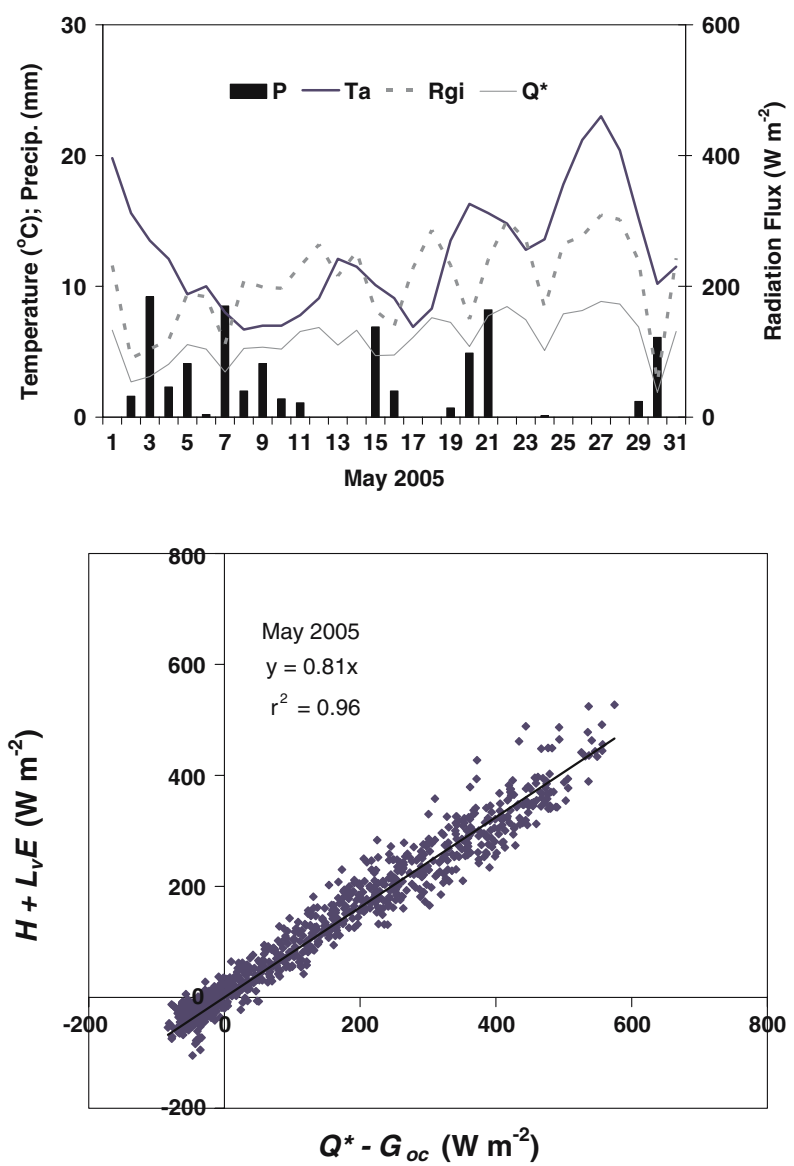

lilies, potatoes, etc.), dew is best calculated with a more extended crop model (Jacobs et al. $2005 ; 2006 b)$.

\section{Results and Discussions}

The month of May 2005 was first selected and analyzed in detail. This month was relatively sunny with an incoming amount of global irradiation of $210 \mathrm{~W} \mathrm{~m}^{-2}$ (normal value $190 \pm 25 \mathrm{~W} \mathrm{~m}^{-2}$ ), with a mean air temperature of $12.6^{\circ} \mathrm{C}$ (normal value $12.6 \pm 1.5^{\circ} \mathrm{C}$ ) and a total precipitation of $64.6 \mathrm{~mm}$ (normal value $55 \pm 25 \mathrm{~mm}$ ). The main meteorological variables for this month are plotted in Fig. 1.

Figure 2 contains the 30-min averages of the available energy vs. the sum of the vertical fluxes according to (4). Here, the surface soil heat flux, $G_{o c}$, was calculated with the caloric technique and no other storage corrections were applied. Moreover, periods with rain events were discarded because of malfunction of the radiometers and the eddy covariance system during these periods. The linear regression forced through the origin is $y=0.81 x$ with $r^{2}=0.96(N=1,194)$, implying that there is an imbalance of $19 \%$, which is high but not an uncommon value (e.g., Laubach et al. 1994; Brotzge and Cranford 2003). 
Fig. 3 Scattergram of the 30-min averages of the available energy versus the convective terms for May 2005. The surface soil heat flux, $G_{o h}$, is calculated with the harmonic analysis technique. Rain periods are discarded because of malfunction of the instruments during these events

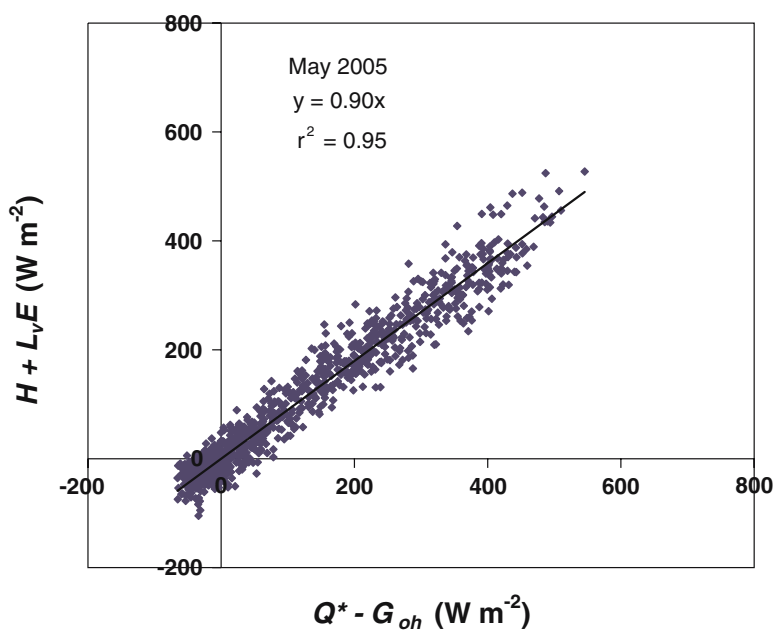

Fig. 4 The courses of the surface soil heat flux corrected with the caloric technique, $G_{o c}$, and corrected with the harmonic technique, $G_{o h}$

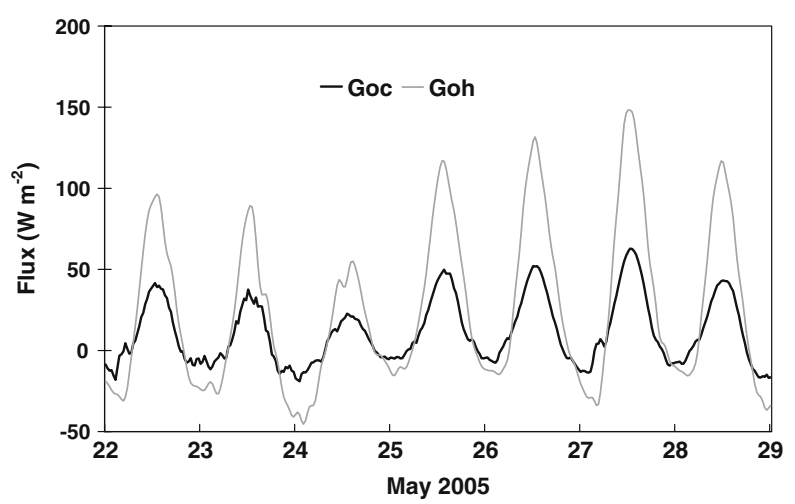

Figure 3 contains the same scattergram as Fig. 2, but now the surface soil heat flux, $G_{o h}$, is calculated with the harmonic analysis technique. The linear regression of Fig. 3 forced through the origin is $y=0.90 x$ with $r^{2}=0.95(N=1,194)$, and we conclude that the application of the harmonic analysis technique improves the imbalance by $9 \%$, which is significant. The same improvement was found in an earlier study for a dry desert soil (Heusinkveld et al. 2004). It must be noted that the caloric technique can also be considerably improved if the temperature profile above the soil heat flux plate is measured in more detail, e.g., by placing more temperature sensors in the soil. In our case we have only one sensor available and the soil flux plate is relatively deeply buried $(75 \mathrm{~mm})$.

It is interesting to analyze the difference in the surface soil heat flux between the caloric and the harmonic correction technique, and in Fig. 4 both fluxes have been plotted for a 1-week period in May 2005. According to Fig. 4, we conclude that in our case the harmonic correction technique results in a soil surface heat flux that is greater by nearly a factor of two relative to the caloric technique.

Figure 5 contains the 30-min averages of the available energy versus the sum of the vertical heat fluxes, corrected for photosynthetic energy and all storage terms as given in (5). The linear regression of Fig. 5 forced through the origin is $y=0.96 x$ with $r^{2}=0.97(N=$ $1,194)$. In order to obtain a better insight into the importance of the various storage terms, 
Fig. 5 Scattergram of the 30-min averages in May 2005 of the available energy versus the convective terms corrected for photosythetic energy, for crop, air and dew water enthalpy and for air moisture changes. Rain periods are discarded because of malfunction of the instruments during these events

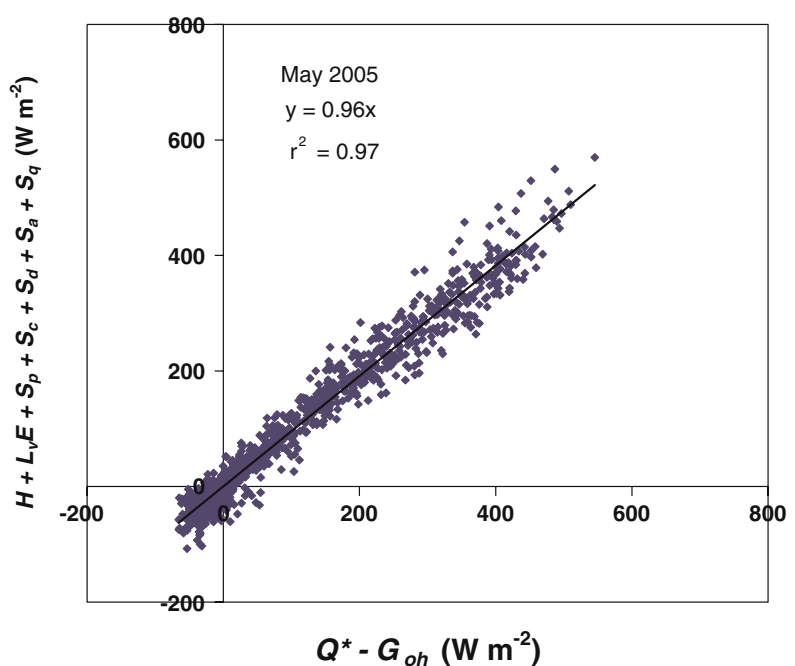

Table 2 The contribution of the storage terms to the surface energy balance closure

\begin{tabular}{llllll}
\hline & $S_{p}$ & $S_{c}$ & $S_{d}$ & $S_{a}$ & $S_{q}$ \\
\hline Additional improvement & $3.0 \%$ & $0.5 \%$ & $0.1 \%$ & $2.0 \%$ & $0.5 \%$ \\
\hline
\end{tabular}

$S_{p}=$ photosynthesis flux, $S_{c}=$ crop enthalpy change, $S_{d}=$ canopy dew water enthalpy change, $S_{a}=$ air enthalpy change, $S_{q}=$ atmospheric moisture change

the percentage improvement by the various storage terms to the energy budget closure is presented in Table 2. It appears that the air enthalpy term, $S_{a}$, gives the highest contribution (about 2\% improvement) and the sum of $S_{c}+S_{q}+S_{d}$ about a $1 \%$ improvement. Despite the low contribution of all individual storage terms, the total correction of about $4 \%$ is also significant for the closure of the surface energy budget.

It is interesting to investigate whether there is a difference in the closure between a socalled fine weather period and an unsettled period, and consequently in Fig. 6 a distinction has been made between a so-called fine weather period (upper panel) between May 25-29, and the unsettled period (lower panel) between May 2 and 22. The results indicate that the fine weather period shows an even better closure $\left(y=0.99 x, r^{2}=0.99\right.$ and $\left.N=240\right)$ than the total month of May, while the unsettled period shows a somewhat less good closure ( $y=0.95 x, r^{2}=96$ and $N=960$ ). The Netherlands, however, is a mid-latitude coastal country where unsettled days dominate the weather, and that is why the total monthly results nearly agree with the unsettled period.

The same procedure was carried out for the month of August 2005, which was also relatively sunny with an incoming amount of global irradiation of $170 \mathrm{~W} \mathrm{~m}^{-2}$ (normal value $165 \pm 20 \mathrm{~W} \mathrm{~m}^{-2}$ ), a mean air temperature of $15.8^{\circ} \mathrm{C}$ (normal value $14.6 \pm 1.4^{\circ} \mathrm{C}$ ), and a total precipitation of $59.0 \mathrm{~mm}$ (normal value $56 \pm 19 \mathrm{~mm}$ ). The main meteorological variables for this month are plotted in Fig. 7.

Figure 8 contains the 30-min averages of the available energy versus the sum of the vertical heat fluxes, corrected for photosynthetic energy and all storage terms as given in (5). 
Fig. 6 Upper panel: Scattergram of the 30-min averages for fine days in May 2005 of the available energy versus the convective photosynthetic energy, for crop, air and dew water enthalpy and for air moisture changes. Lower panel: Scattergram of the 30-min averages for unsettled days in May 2005 of the available energy versus the convective terms corrected for photosynthetic energy, for crop, air and dew water enthalpy and for air moisture changes terms corrected for
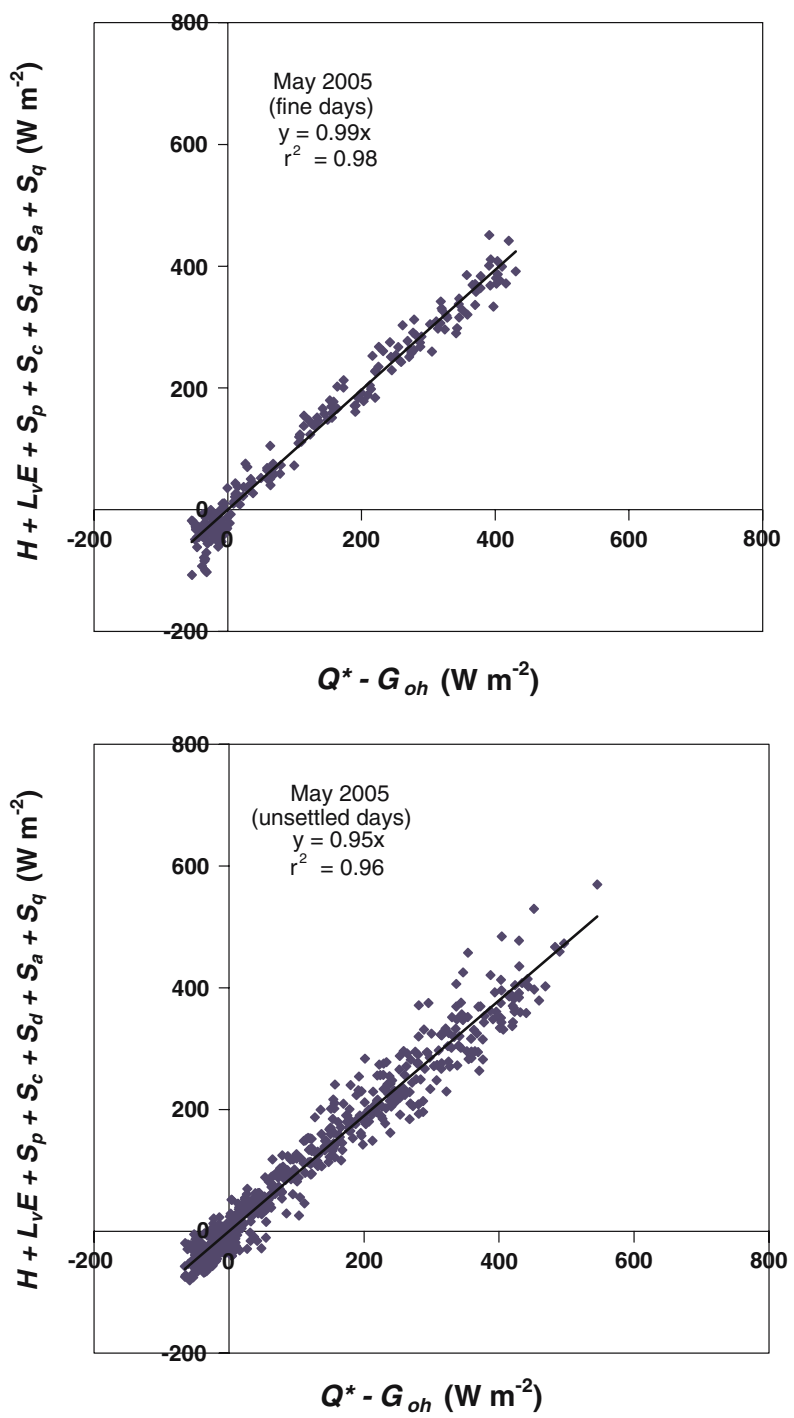

Fig. 7 Course of the daily mean air temperature $\left(T_{a}\right)$, daily total precipitation $(P)$, daily mean shortwave incoming $\left(R_{g i}\right)$ and net radiation $\left(Q^{*}\right)$ for August 2005

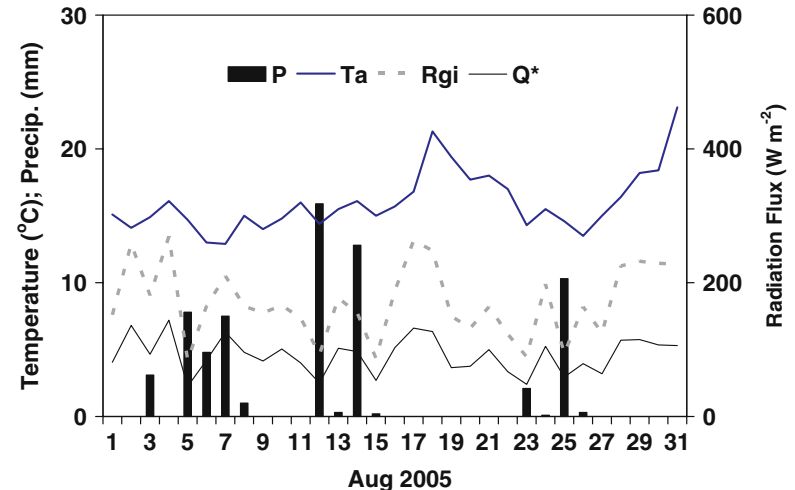


Fig. 8 Scattergram of the 30-min averages in August 2005 of the available energy versus the convective terms corrected for photosythetic energy, for crop, air and dew water enthalpy and for air moisture changes. Rain periods are discarded because of malfunction of the instruments during these events

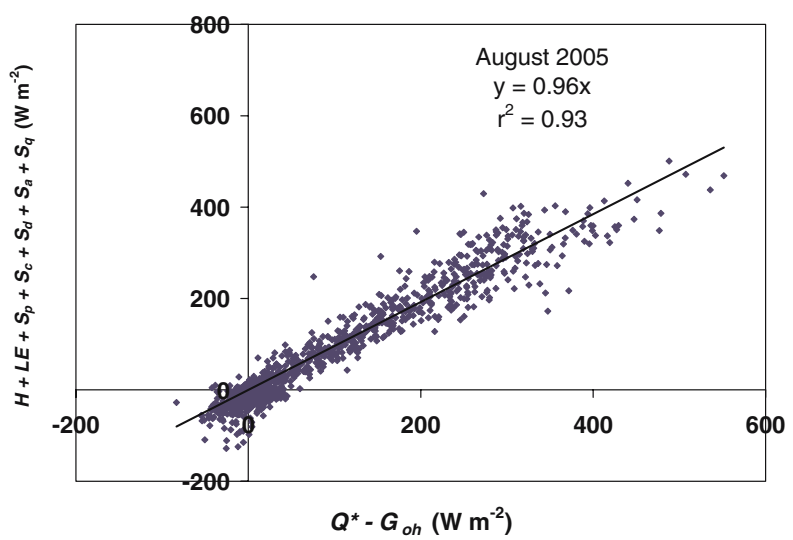

Fig. 9 The course of evapotranspiration, $L_{v} E$, measured by the EC technique, along with the free water condensation/evaporation modelled with the dew model (10) for five consecutive days in May 2005

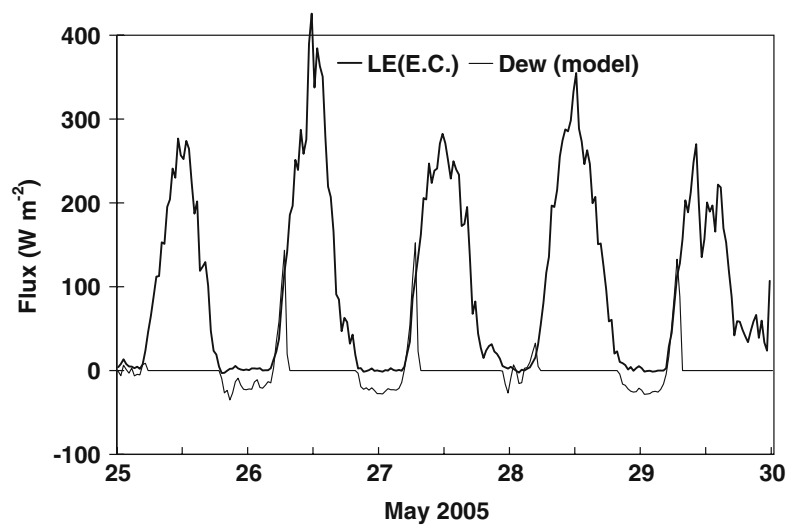

The linear regression of Fig. 8 forced through the origin is $y=0.96 x$ with $r^{2}=0.93(N=$ 1,298). August thus provided more or less the same results as for May.

During most nights, the imbalance of the surface energy budget is relatively much larger than during daytime, in particular during calm nights (friction velocity $u_{*}<0.1 \mathrm{~m} \mathrm{~s}^{-1}$ ). During calm nights, turbulence is suppressed and the eddy covariances become ill-defined since these conditions are non-stationary and non-homogeneous (Van de Wiel et al. 2003; Steeneveld et al. 2006). Traditionally, nighttime fluxes were of little importance and often ignored because the vertical heat fluxes are small in comparison to the daytime fluxes. In the last decade, estimating accurate nighttime fluxes became increasingly important because of the importance of the nighttime respiration flux in the total carbon dioxide budget (Culf et al. 2004).

When we compare, for example, the measured nighttime dew flux with the eddy covariance (EC) technique against the modelled dew flux according to (10), a large discrepancy exists between both assessments. An example of this discrepancy is demonstrated in Fig. 9, where for five consecutive nights the modelled dew fluxes are compared with the measured EC latent heat fluxes. The EC results scatter around the zero flux line during the night whereas the dew model gives a clear condensation flux. These dew model results were compared with lysimeter results and appeared to agree well (Jacobs et al. 2006a). This motivated us to substitute the nighttime EC fluxes by the modelled fluxes if $u_{*}<0.1 \mathrm{~m} \mathrm{~s}^{-1}$. In fact, the 
estimate by (10) is useful in low wind speed cases so long as the latent heat flux $<0$, which typically occurs for $u_{*}<0.03 \mathrm{~m} \mathrm{~s}^{-1}$ (Holtslag and DeBruin 1988; Jacobs et al. 2006a).

\section{Conclusions}

We studied the energy budget closure at a grassland site in the Netherlands, and quantified the surface soil heat flux with the caloric as well as with the harmonic analysis technique. Assessments were made for all possible storage terms of the vegetation-atmosphere system. Moreover, the canopy assimilation flux was also taken into account in the surface energy budget. The following main conclusions can be drawn from the study:

(1) The harmonic analysis technique gives a better assessment of the soil surface heat flux if the soil temperature profile above the heat flux sensor is measured with only a very limited number of sensors. In this study an increase of the energy budget closure of $9 \%$ is achieved with this technique.

(2) The assimilation energy improved the energy closure budget for our mid-latitude grassland area by $3 \%$, implying that the assimilation flux should not be ignored in a grassland area.

(3) If the storage terms are taken into account, an additional 3\% in the energy closure is achieved, and it appeared that the enthalpy storage in the air layer between the EC system and the ground surface gave the most important contribution (2\%) and the other storage terms contributed an improvement of $1 \%$.

(4) Under low wind conditions $\left(u_{*}<0.1 \mathrm{~m} \mathrm{~s}^{-1}\right)$ sensible and latent heat fluxes are not measured well by the EC system. During these periods the heat fluxes are better estimated by model calculations (at least in the case of dew).

Acknowledgements We thank the technical staff of our group for doing calibrations and maintenance of the instrumentation during the experimental period. This work was partly supported by the Dutch Climate Changes Spatial Planning programme, Project ME1, "Integrated observations and modelling of greenhouse gas budgets at the ecosystem level in The Netherlands".

\section{References}

Atzema AJ (1993) The effect of the weather on the drying rate of cu diploid and tetraploid perennial ryegrass (Lolium perenn L.) and diploid hybrid ryegrass (Lolium perenne $\times$ L. multiflorum) Grass Forage Sci 48:.362-368

Bolle HJ, André J-C, Arrue JL et al (1993) EFEDA: European field experiment in an desertification-threatened area. Ann Geophys 11:173-189

Braud I, Noilhan J, Bessemoulin J, Mascart P, Haverkamp P, Vauclin R (1993) Bareground surface heat and water exchanges under dry conditions. Boundary-Layer Meteorol 66:173-200

Brotzge JA, Crawford KC (2003) Examination of the surface energy budget: a comparison of Eddy Correlation and Bowen Ratio measurement systems. J Hydrometeorol 4:160-178

Campbell GS, Norman JM (1998) An introduction to environmental biophysics. Springer Verlag, 286 pp

Culf AD, Foken T, Gash JH (2004) The energy balance closure problem. In: Kabat P, Claussen M, Dimeyer PA, Gash JH, De Guenni LB, Meybeck M, Pielke M, Vorosmarty RA, Hutjes CJ, Lutkemaier RW (eds) Vegetation, water, humans and the climate. Springer Verlag, $566 \mathrm{pp}$

De Vries DA (1963) Thermal properties of soils. In: Van Wijk WR (ed) Physics of plant environment, North Holland Publ, Amsterdam, 385 pp

Finnigan JJ, Clement R, Malhi Y, Leuning R, Cleugh HA (2003) A re-evaluation of long-term measurement techniques. Part I: averaging and coordinate rotation. Boundary-Layer Meteorol 107:1-48

Foken T (2006) Angewandte meteorologie. Springer Verlag, Berlin 290 pp 
Foken T, Wichura B (1996) Tools for quality assessment of surface-based flux measurements. Agric Forest Meteorol 78:83-105

Foken T, Wimmer F, Mauder M, Thomas C, Liebethal C (2006) Some aspects of the energy balance closure problem. Atm Chem Phys Discuss 6:4395-4402

Fritschen LJ, Gay LW (1979) Environmental instrumentation. Springer Verlag, New York, 216 pp

Garratt JR, Segal M (1988) On the contribution to dew formation. Boundary-Layer Meteorol 45:209-236

Garratt JR (1992) The atmospheric boundary layer. Cambridge University Press, Cambridge, 316 pp

Heusinkveld BG, Jacobs AFG, Holtslag AAM, Berkowicz SM (2004) Surface energy balance closure in an arid region: role of soil and heat flux. Agric Forest Meteorol 122:21-37

Holtslag AAM, De Bruin HAR (1988) Applied modeling of nighttime surface energy balance over land. J Appl Meteorol 27:689-704

Jacobs AFG, Heusinkveld BG, Holtslag AAM (2003) Carbon dioxide and water vapour flux densities over a grassland area in The Netherlands. Int J Climatol 23:1663-1675

Jacobs AFG, Heusinkveld BG, Klok EJ (2005) Leaf wetness within a Lily canopy. Meteorol Applications 12:193-198

Jacobs AFG, Heusinkveld BG, Wichink Kruit RJ, Berkowicz SM (2006a) Contribution of dew to the water budget of a grassland area in the Netherlands. Water Resaur Res 42:W03415, doi:10.1029/2005WR004055

Jacobs AFG, Heusinkveld BG, Kessel GJT (2006b) Measurement and simulation of leaf wetness duration within a potato canopy. Neth J Agric Sci 53:151-166

Laubach J, Raschendorfer M, Kreilein H, Gravenhorst G (1994) Determination of heat and water vapour fluxes above a spruce forest by eddy correlation. Agric Forest Meteorol 71:373-401

Mayocchi CL, Bristow KL (1995) Soil surface heat flux: some general questions and comments on measurements. Agric Forest Meteorol 75:43-50

McCaughy JH, Saxon WL (1988) Energy balance storage terms in a mixed forest. Agric Forest Meteorol 44:1-18

Meyers TP, Hollinger SE (2004) An assessment of storage terms in the surface energy balance of maize and soybean. Agric Forest Meteorol 125:105-115

Mogensen VO (1970) The calibration factor of heat flux meters in relation to the thermal conductivity of the surrounding medium. Agric Forest Meteorol 7:401-410

Nobel PS (1974) Introduction to biophysical plant physiology. Freeman, New York, 260 pp

Sakai RK, Fitzjarrald D, Moore KE (2001) Importance of low-frequency contributions to eddy fluxes observed over rough surfaces. J Appl Meteorol 40:2178-2192

Schuepp PH, Leclerc MY, MacPherson JI, Desjardin RL (1990) Footprint prediction of scalar fluxes from analytical solutions of the diffusion equation. Boundary-Layer Meteorol 50:355-373

Snel S (2004) Soil-atmosphere exchange of $\mathrm{CO}_{2}$. MSc Thesis, Wageningen University, Dept. Meteorology and Air Quality, $98 \mathrm{pp}$

Steeneveld GJ, Vande Wiel BJH, Holtslag AAM (2006) Modeling the evolution of the atmospheric boundary layer coupled to the land surface for a three day period in CASES-99. J Atmos Sci 63:920-935

Tsvang LR, Federov MM, Kader BA, Zubovskii SL, Foken T, Richter SH, Zeleny YA (1991) Turbulent exchange over a surface with chess-board-type inhomogeneities. Boundary-Layer Meteorol 55:141-160

Van de Wiel BJH, Moene AF, Hartogensis OK, De Bruin HAR, Holtslag AAM (2003) Intermittent turbulence in the stable boundary layer over land. Part III: a clasification for observations during CASES-99. J Atmos Sci 60:2509-2522

Verhoef A (1995) Surface energy balance of shrub vegetation in the Sahel. PhD thesis, Wageningen University. 247 pp

Von Randow C, Sá LDA, Prasad G, Manzi A, Kruijt B (2002) Scale variability of atmospheric surface fluxes of energy and carbon over a tropical rain forest in South-West Amazonia. I. Diurnal conditions. J Geoph Res 107:8062, doi:10.1029/2001JD000379

Wilson KB, Goldstein A, Falge E, Aubinet M, Baldocchi D, Berbigier C, Ceulemans R, Dolman H, Field C, Grelle A, Ibrom A, Law B, Kowalski A, Meyers T, Moncrieff J, Monson R, Oecal W, Tenhunen J, Valentini R, Verma S (2002) Energy balance closure at FLUXNET sites. Agric Forest Meteorol $113: 223-243$ 